\title{
Berlin universities mired in budget crisis
} to be debated in Berlin's parliament this week proposing a cut of nearly DM200 million (US $\$ 137$ million) in the overall budget of the city's three universities. It says that this cut should be achieved by closing or merging a number of specific faculties, and by reducing student numbers by 15 per cent.

The Berlin legislature was also scheduled to debate amendments to the city's universities law which would give its government the power to enforce faculty closures against the wishes of the universities. But the universities have reacted angrily both to the threat to their constitutional autonomy - under which they are in principle free to make their own academic decisions - and to the extent of the cuts.

The universities point out that, when added to previous cuts imposed since reunification in 1990, the total cuts are equivalent to the costs of running a whole university and medical school. They also emphasize that any enforced reduction in student numbers would conflict with another constitutional right: that of students with a school leaving certificate to a university education.

But, far from being united by their shared adversity, the universities - the Humboldt in the east and the Free and Technical universities in the west - have been thrown even deeper into the conflict that has been raging in Berlin ever since the full economic costs of reunification first became apparent.

Hostilities between the three universities began with the passing of the universities law in 1993. This predicted a lowering of the total universities budget by DM130 million within ten years, and a reduction in the number of students from 115,000 to 100,000 . At that time the two west German universities were asked to bear the brunt of the savings, while considerable investment was made in the Humboldt University to raise it to western standards. The Humboldt, however, was required to halve its staff.

Last year, as the city's financial crisis deepened, the target for budget reductions was increased to DM288 million. The government wanted the cuts to be achieved
Munich. An emergency budget bill was due

through agreed mergers of departments and faculties whose courses were duplicated.

But the universities have been very slow to reach agreements. Negotiations between them became increasingly hostile, and positions stubbornly entrenched. As Berlin plunges towards bankruptcy, the proposed cuts bring to DM484 million the total saving on annual budget expected to be achieved by 2003 , and the government does not want to wait much longer for universities to decide on how they should be implemented.

The government's new proposal to parliament would allow universities to make suggestions for implementing cuts. But, if they do not do so within a defined time, it would enforce its own suggestions. The universities claim that the faculties targeted by the government for closure have been chosen randomly, but both the Technical University and the Humboldt University are refusing on principle to suggest alternatives.

Gunther Kaindl, vice-president of the science and research faculty of the Free University, which must cut back around DM40 million per year, says this attitude is not helpful. The Free University senate plans to offer an alternative to the plan to close the informatics department, with a saving of DM4 million, through restructuring of mathematics and materials sciences disciplines.

But such cooperation has its own limits: the university has no alternative suggestion to the closure of its school of dentistry which would save DM15 million. Kaindl points instead to the expensive new chemistry department, being built for the Humboldt University on a green-field site, when, he says, both west Berlin universities already have large and modern laboratories. "This all makes discussions between the universities very difficult," he says.

According to Bert Flemming of the social democrats - one of Berlin's coalition partners - a possible solution to the problem of restructuring could be to set up a committee made up of representatives of all three universities and the ministry for science and research, to make common decisions.

\section{Japan agrees to pay HIV-blood victims}

Tokyo. After a seven-year court battle, hundreds of Japanese last week finally reached a compensation settlement with the government and pharmaceutical companies over their infection in the mid-1980s by blood coagulants that had not been heattreated to kill viruses.

The plaintiffs, which consist of two groups in Tokyo and Osaka, decided to accept the out-of-court settlement after the Ministry of Health and Welfare and the five blood product manufacturers they were suing formally apologized and admitted responsibility for the disaster.

Days before the settlement was reached, the Tokyo District Prosecutors Office announced that it had set up a team of six prosecutors to investigate possible criminal charges. Prominent among those who are to be investigated is Takeshi Abe, who headed an AIDS study group which was set up in the ministry in June 1983.
Up to now, he says, the universities have been opposed to such a committee, as it would allow outsiders to become involved in decisions that should be made internally. But, faced with the larger threat to auton-

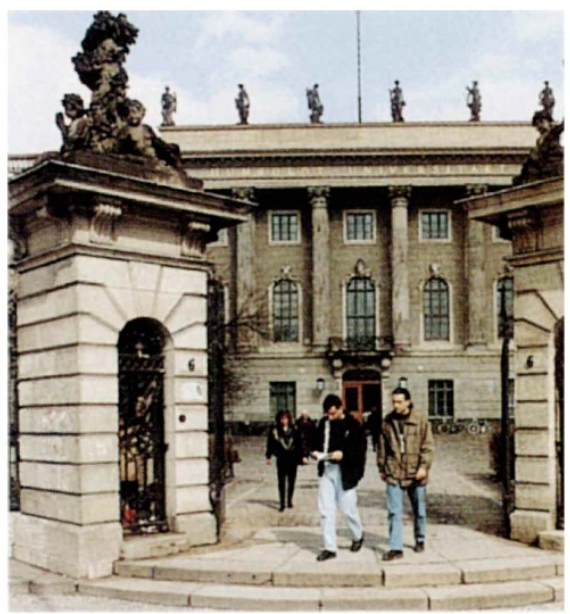

Taking a stand: Humbolt University is not volunteering cuts to Berlin's government.

omy posed by the amendment to the universities act, he says, they may be more willing, and has been lobbying hard among his parliamentary colleagues for this solution.

Some moves towards this system of decision making are already introduced in the emergency budget bill. This would require universities, in discussion with politicians and community representatives, to agree on how to share between their science faculties an additional cut of DM14 million, not earmarked by the government for particular departments.

A similar committee is expected to distribute a 20 per cent cut on Berlin's medical faculties, which have suffered particularly from the post-reunification restructuring (see Nature 369, 431; 1994). Peter Gaehtgens, the Free University's vice-president for medicine, reluctantly accepts this principle, at least as a short-term measure. "It is quite apparent that the universities cannot come to a solution which is compatible with the economic situation", he admits.

But universities are unlikely to want the system to be extended beyond particularly difficult - or expensive - disciplines, he says. "That would be too intrusive".

The issue of student number reduction is equally problematic. Earlier this month, a Berlin court ruled in favour of 14 students who had been refused admittance to Berlin's medical schools because numbers had been reduced in previous cuts, agreeing that this conflicted with their constitutional right to study. The science and research ministry is now considering taking the matter to the constitutional court to clarify whether economic difficulties can be allowed to override this right.

Alison Abbott 